Çukurova Üniversitesi Mühendislik Mimarlık Fakültesi Dergisi, 30(1), 223-229 ss., Haziran 2015

Çukurova University Journal of the Faculty of Engineering and Architecture, 30(1), pp. 223-229, June 2015

\title{
Kömür Damarlarının Gaz İçeriğinin Belirlenmesi; Örnek Bir Uygulama
}

\author{
Cem ŞENSÖĞÜT ${ }^{*}$, Kemal BARIŞ ${ }^{2}$ \\ ${ }^{1}$ Dumlupınar Üniversitesi, Mühendislik Fakültesi, Maden Mühendisliği Bölümü, Kütahya \\ ${ }^{2}$ Bülent Ecevit Üniversitesi, ZMYO, Madencilik ve Maden Çıkartma Bölümü, Zonguldak
}

Geliş tarihi: 28.05 .2015

Kabul tarihi: 19.06 .2015

\section{Özet}

Artan üretim miktarları ile üretim panolarının daha derinlere ulaşması, çalışılan ayağın önündeki kömür damarlarının gaz içeriğinin belirlenmesine yönelik talebi de beraberinde getirmiştir. Aynı zamanda kömür damarlarının gaz içeriğini etkileyen parametrelerin birbirleriyle olan ilişkilerinin biliniyor olması, doğru bir tahmin için son derece önemlidir. Elde edilen verilerin değerlendirilmesi, özellikle işçi sağlığı ve iş güvenliği açısından ve verimli bir işyeri planı ortaya koyulması yönünden ayrı bir hassasiyete sahiptir. Bu çalışmada, kömürlerin gaz içeriğinin tespitine yönelik yapılan çalışmalar ile birlikte, Gediz'de (Kütahya) bir kömür ocağından elde edilen numunelerin gaz potansiyeli araştırılmış yapılan deneysel çalışmalar detayları ile birlikte verilmiştir.

Anahtar Kelimeler: Kömür, Gaz içeriği, Yeraltı kömür madenciliği, Ani püskürme

\section{The Determination of Gas Content of Coal; A Case Study}

\begin{abstract}
Increased production rates and deeper panel locations have brought about the demand for the determination of the gas content of coal beds ahead of the working face. It is also important to know the association of the parameters with each other for an accurate estimation of gas content of the coal seams. Evaluation of the data obtained has a distinct precision specifically for the occupational health and safety as well as realizing an efficient workplace. In the present work, the practices towards the determination of gas content of the coal are outlined together with the explanation of an experimental work carried out on the coal samples taken from a colliery in the province of Gediz (Kütahya).
\end{abstract}

Keywords: Coal, Gas content, Underground coal mining, Sudden outburst

\footnotetext{
* Yazışmaların yapılacağı yazar: Cem ŞENSÖĞÜT, Mühendislik Fakültesi, Maden Mühendisliği Bölümü, Kütahya.sensogut@dpu.edu.tr
} 


\section{GİRIŞ}

Madencilik, insanlık tarihi kadar eski olup insanoğlunun gereksinimlerini karşılamak amaciyla yeraltı ve yerüstü faaliyetlerini bünyesinde barındıran, gerekli önlemler alınmadığında ciddi kazalanmalara ve meslek hastalıklarına yol açabilen önemli bir iş alanıdır. Özellikle yeraltı kömür madenciliği, doğası gereği diğer madencilik alanlarından daha büyük risklere sahiptir. Kömürlerin oluşumu sırasında geçirmiş olduğu fizikokimyasal süreç, yapılarında pek çok gaz komplekslerinin oluşumuna ve depolanmasına sebep olmaktadır. Metan \%80-95 [1-2] oraniyla çoğunlukla birinci sırada yer almakta ve hatta bu oluşum bazen $25 \mathrm{~m}^{3} / \mathrm{t}$ [3] gibi çok tehlikeli değerlere ulaşabilmektedir. Kömür içerisinde bulunan bu gaz, zamanla kömürü terk etmekte ve bazen bu ayrılış ani gaz/kömür püskürmesi şeklinde oluşabilmektedir ki bu durum çoğunlukla can ve mal kaybı ile sonuçlanmaktadır [4].

Günümüzde bu olayın mekanizmasının tam olarak çözülebildiğini söylemek mümkün olmamakla beraber yapılan bazı çalışmalar ile sebep ve sonuç ilişkisine 1 şık tutulmaya çalışılmaktadır. Olayın içersisinde yer aldığı hemen tüm araştırmacılar tarafindan kabul edilen parametreleri; jeolojik yapı, kömür yapısının gaz içeriği, madencilik aktiviteleri ve kömür yapısının mekanik mukavemeti olarak sıralayabiliriz [5-6].

$\mathrm{Bu}$ parametrelerden kömürün sahip olduğu gaz içeriğinin tespiti, ani gaz püskürme riskinin belirlenmesine yönelik pek çok pratik yaklaşım içinde kullanılmaktadır.

\section{KÖMÜRDEKİ GAZ İÇERIĞİ}

Bitkisel organizmalar, çeşitli aşamalardan geçerek yüksek sıcaklık ve basınç gibi fizikokimyasal olaylar sonucunda kömürleşmektedir. Bu süreçte, yüksek oranlarda gaz oluşmakta ve oluşan gaz ya kömür ya da yan kayaç içerisinde depolanmaktadır. Kömür içerisinde karbondioksit, azot, su ve diğer hidrokarbonların da bulunmasına rağmen söz konusu gazın büyük bir kısmını metan oluşturmaktadır. Bu gazın büyük bir bölümü var olan denge sistemi içerisinde kömür damarları ile çevre tabakaları içinde serbest ve gözeneklerin yüzeylerine soğurulmuş durumdadır. Söz konusu bu gaz, kömür damarları içinde a) mikro gözeneklerin iç yüzeylerinde adsorbe olarak, b) kömürün moleküler yapısı içine absorbe olarak, c) çatlaklarda serbest olarak ve d) yeraltı suyunda çözelti olarak bulunur [7-9]. Yeraltında daha derinlere gidildikçe gaz, gözenek boşluklarında serbest gaz olarak depolanmaktadır [10].

Mikro gözenek hacmi ve kapasitesi ve yüzey alanı belirleme için en yaygın kullanılan yöntemlerden birisi, düşük basınçta $\mathrm{CO}_{2}$ adsorpsiyonu ölçümleri ve Dubinin-Radushkevich (D-R) yaklaşımıdır [11-13]. Gaz adsorpsiyonu genel olarak yüzey alanı ve dolayısı ile mikro gözenek hacmi ile ilişkilidir [14-16]. Kömürün birçok diğer özelliği; adsorpsiyon verileri, mikro gözenek hacmi ve kapasitesi ile yüzey alanının belirlenmesinde etkilidir [12,16-19]. Depolanan gaz içeriğini aynı zamanda jeolojik ve hidrojeolojik faktörler de etkilemektedir [20]. Kömür damarlarının gaz içeriğinde etkin olan faktörler temel olarak üç başlık altında verilebilir [21] (Şekil 1).

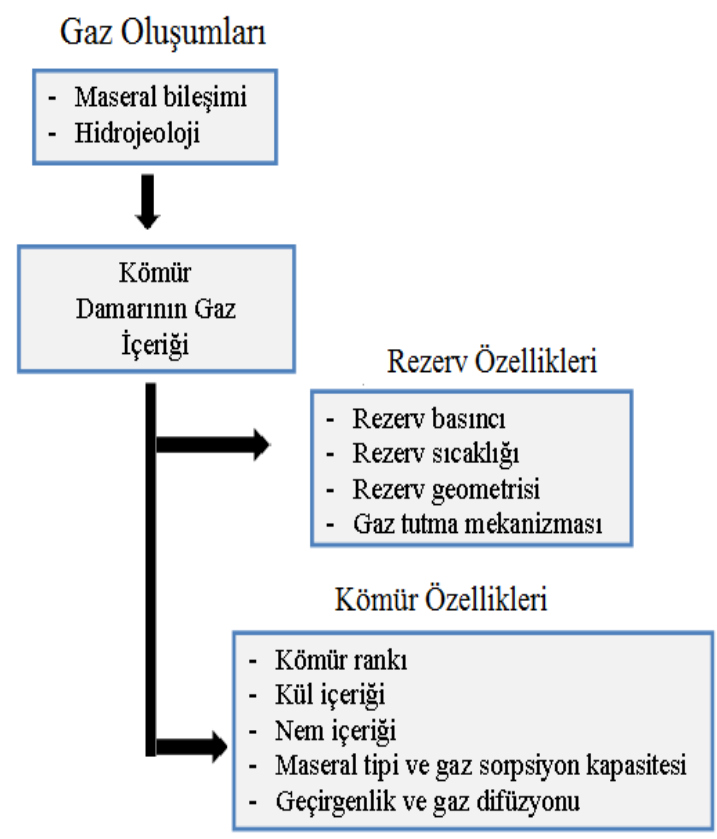

Şekil 1. Kömürün gaz içeriğini etkileyen kömür özellikleri 


\section{KÖMÜRÜN ÖZELLİĞİ}

Kömür üretimi gerçekleştirilen yeraltı ocağına ait jeolojik tabaka dizilimi Şekil 2'de ve bölgeye ait jeolojik harita Şekil 3'de verilmiştir.

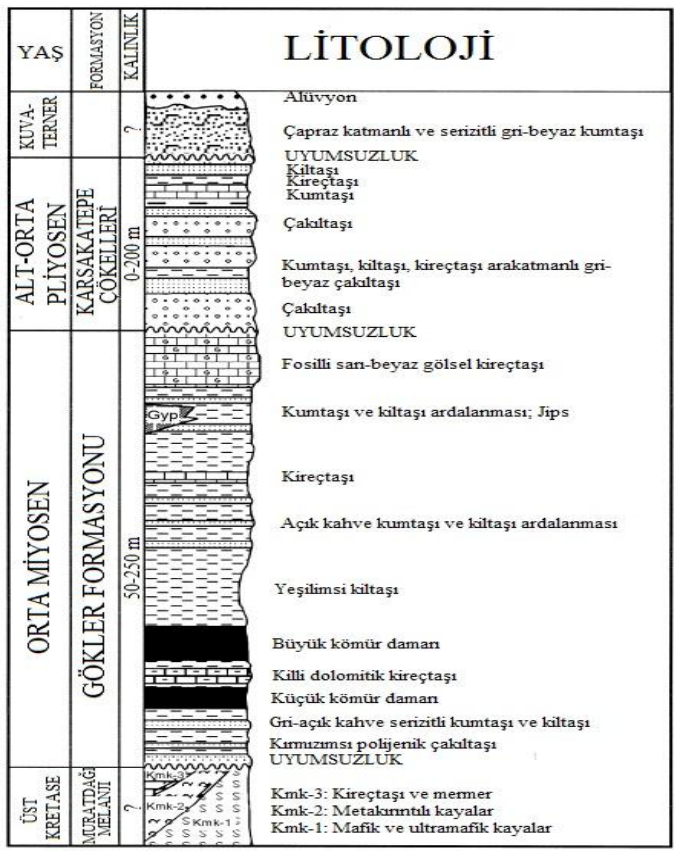

Şekil 2. Gökler kömür sahasının jeolojik tabaka dizilimi [22]
Ayrıca, işletmeye ait tam kömür analizleri Çizelge 1'de görülmektedir [23-24].

Çizelge 1. Gediz yöresi kömürlerin tam analizi

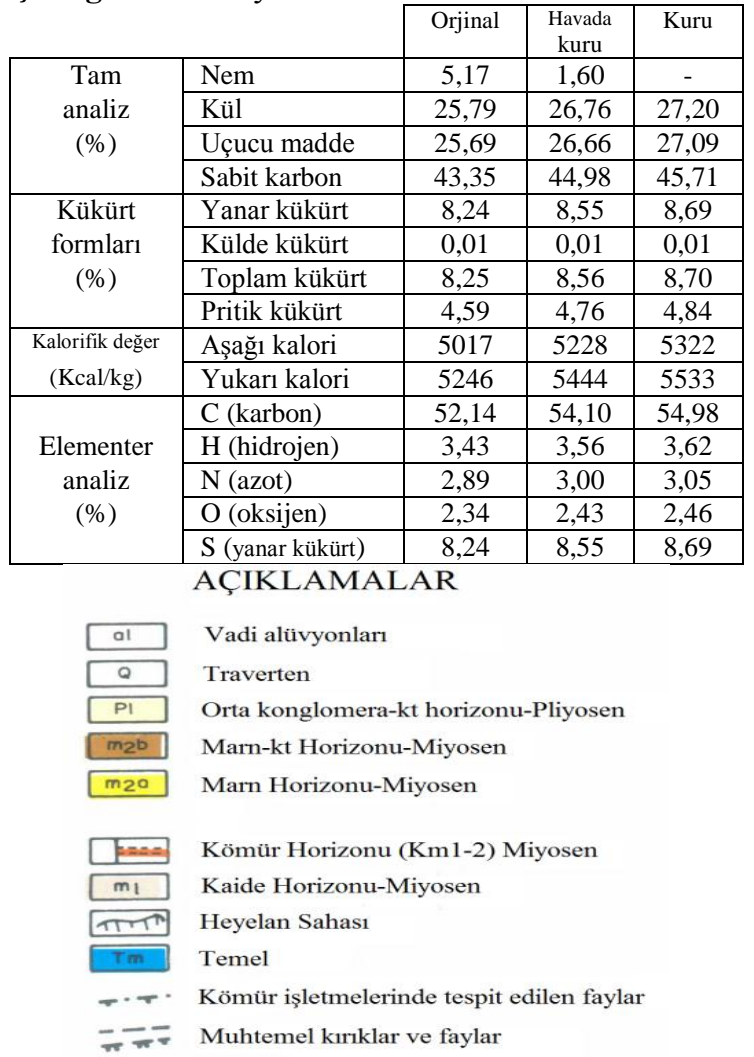

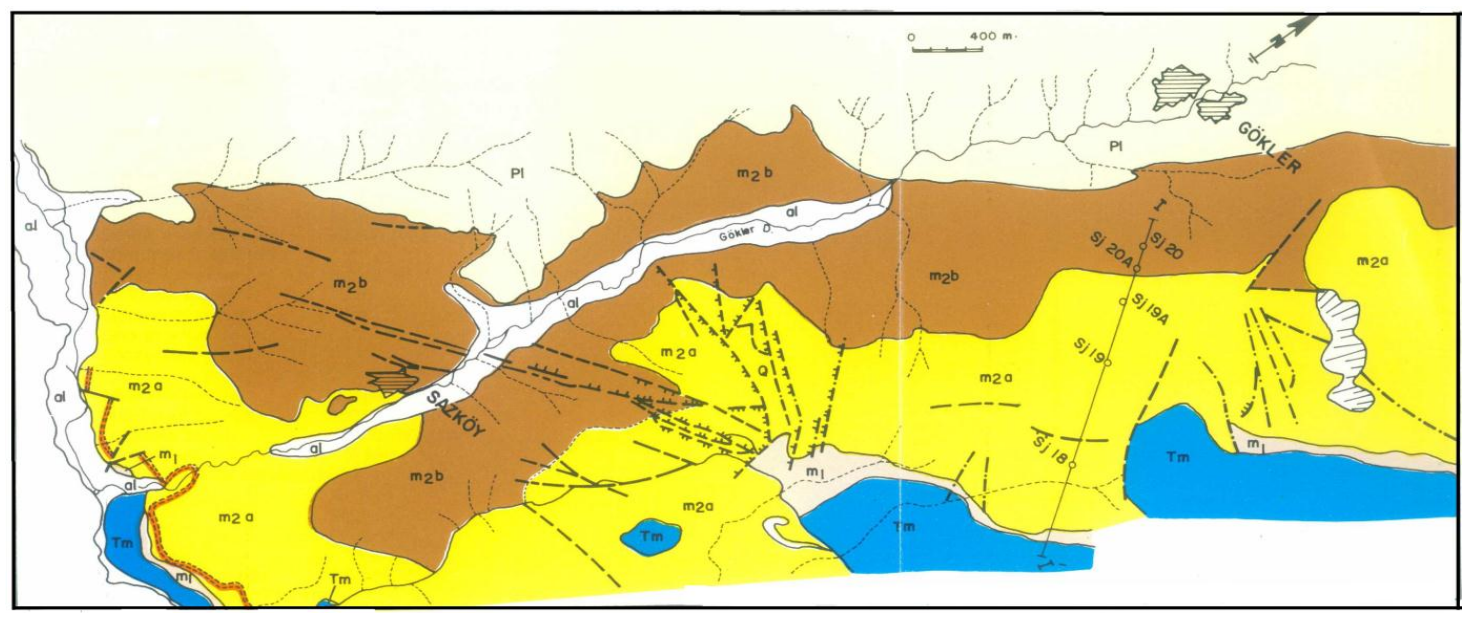

Şekil 3. Bölgeye ait jeolojik harita [25] 


\section{KÖMÜRÜN GAZ İÇERIĞİNIN TESPITI}

CEN-MA şirketine ait Kütahya ili Gediz ilçesi sınırları içerisinde yer alan yeraltı linyit ocağında; AS3980-1990 standardında tanımlanan şekilde doğrudan desorpsiyon yöntemi (hılı desorpisyon) uygulanarak ocakta çalışılan kömür damarının gaz içeriğinin belirlenmesine yönelik bir çalışma yürütülmüştür. Doğrudan desorpisyon yönteminde gaz içeriği ölçülecek damardan sondaj ile elde edilen karot örnekleri, içerisinde bilyelerin bulunduğu hava-sızdırmaz bir kapalı kaba aktarılmakta ve ölçümler su ölçeğinden yararlanılarak gerçekleştirilmektedir. Ölçümlerde kullanılan düzenek ve elemanları Şekil 4'de verilmektedir [26].

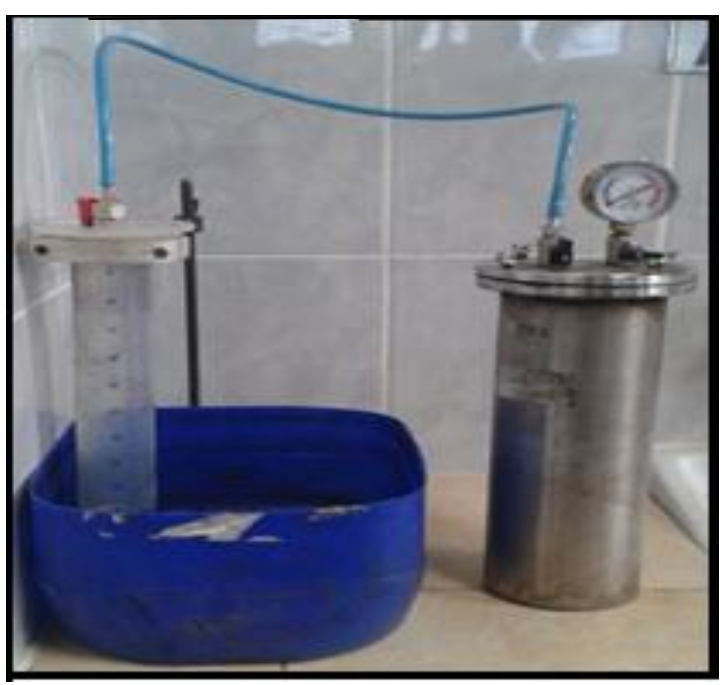

Şekil 4. Su ölçeği ve sızdırmaz örnek kabı

AS3980-1990 standardına göre bir kömür örneğinin toplam gaz içeriği $\left(\mathrm{Q}_{\mathrm{t}}\right)$; kayıp gaz $\left(\mathrm{Q}_{1}\right)$, desorbe gaz $\left(\mathrm{Q}_{2}\right)$ ve kalıntı gazın $\left(\mathrm{Q}_{3}\right)$ ölçülmesi ve bu üç bileşenin toplanması ile saptanmaktadır. $\mathrm{Bu}$ bileşenlerden; $\mathrm{Q}_{1}$ sondaj sırasında alınan numunenin sondaj sirasında ve sizdirmaz kaba aktarılmasına kadar geçen sürede desorbe olan ancak ölçülemeyen gaz yayılımını; $Q_{2}$ sızdırmaz kabın laboratuvar ortamında ölçülen desorbe olan gaz miktarını ve $\mathrm{Q}_{3}$ ise kömür bünyesinde desorbe olabilecek gazın tamamen bitmesiyle kömür matrisinde hapsolan gazın ölçülmesi için örneğin sızdırmaz kap içerisinde (önceden yerleştirilmiş olan bilyeler yardımıyla) -200 meş boyutunda öğütülmesiyle ölçülen gaz miktarını temsil etmektedir. Bu kapsamda, kayıp gaz miktarı $\left(\mathrm{Q}_{1}\right)$ sondaj sırasında ocakta yapılan ölçümlerden yararlanılarak ekstrapolasyon ile hesaplanmakta, desorbe gaz $\left(\mathrm{Q}_{2}\right)$ ve kalıntı gaz $\left(\mathrm{Q}_{3}\right)$ ise ocak dışında ölçülmektedir [26-27].

Her ne kadar AS3980-1990 standardında doğrudan gaz içeriği ölçümlerinin yapılması için gerekli örneklerin tercihen karot örneği olması istense de CEN-MA şirketine ait ocakta karotlu sondaj makinesinin bulunmaması ve hali hazırda çalışılan damar yapısının da karot örneği almaya müsait olmaması (sert ve kırılgan) nedeniyle kömür gaz içeriği ölçümleri için alınacak örneklerin ocakta mevcut bulunan bir darbeli-dönmeli sondaj makinesiyle elde edilecek kırıntılar olmasına karar verilmiştir.

$\mathrm{Bu}$ kapsamda, ocakta kömür gaz içeriğinin ölçümleri için alınan iki örnek, kömür damarını kesen bir galeri içerisinde X: 4321361,044 Y: 722353,562 koordinatlı noktadan gerçekleştirilen bir sondaj ile elde edilmiştir (Şekil 5).

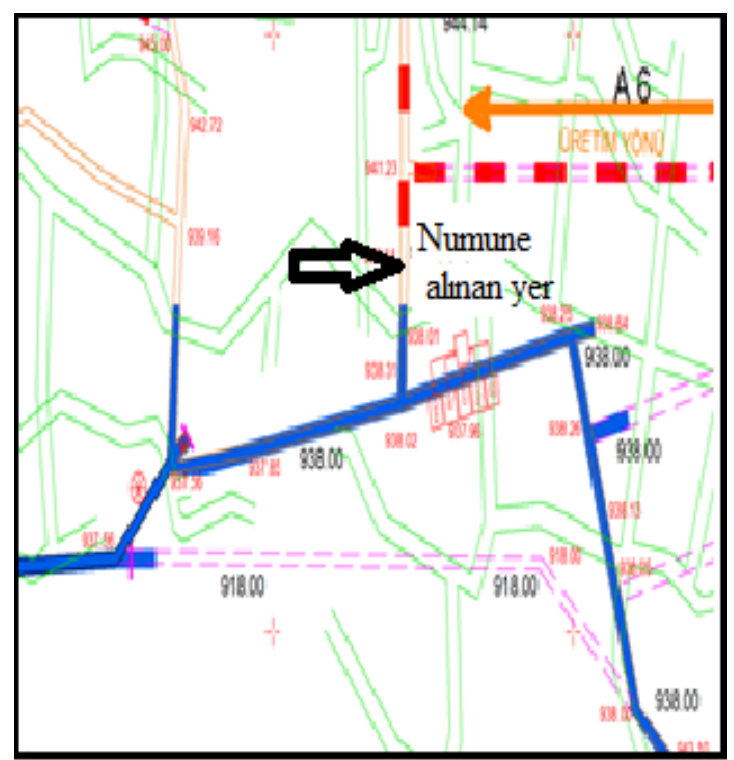

Şekil 5. Gaz içeriği tespiti için alınan örneklerin ocak içerisindeki yeri 
Gaz içeriği ölçümleri için ocakta mevcut bulunan damardan alınan örnek, kullanılan sondaj tijlerinin ancak $3 \mathrm{~m}$ uzunluğunda sondaj yapmaya müsait olması nedeniyle, bu derinlikte açılan sondajdan alınmış ve mümkün olan en kısa zamanda sizdırmaz kaba aktarılarak kayıp gaz $\left(Q_{1}\right)$ ölçümlerine başlanmıştır (Şekil 6). Kayıp gazın hesaplanmasına yönelik olarak yapılan ölçümler ocak içerisinde yaklaşık 30 dakika sürmüş ve gaz yayılımları kayıp gaz $\left(\mathrm{Q}_{1}\right)$ tahmininde kullanılmak üzere kayıt altına alınmıştır. Bunu takiben daha derin bir noktadan örnek almak üzere burgulu bir sondaj makinesi temin dilmiş ve yaklaşık $5 \mathrm{~m}$ derinliğinde bir sondaj daha gerçekleştirilmiştir. Ancak, kömür yapısının oldukça sert ve kırılgan olması ve dolayısıyla burgulu sondaj sirasinda sondaj makinesinin balansının bozulmasına bağlı olarak $5 \mathrm{~m}$ derinliğindeki sondajdan sağlıklı bir şekilde örnek alınamamıştır (balans bozukluğu nedeniyle sondaj deliği genişlemiş ve $5 \mathrm{~m}$ derinlikten elde edilmesi hedeflenen örnek içine sondajın başlangıç noktasındaki kömürler de karışmıştır).

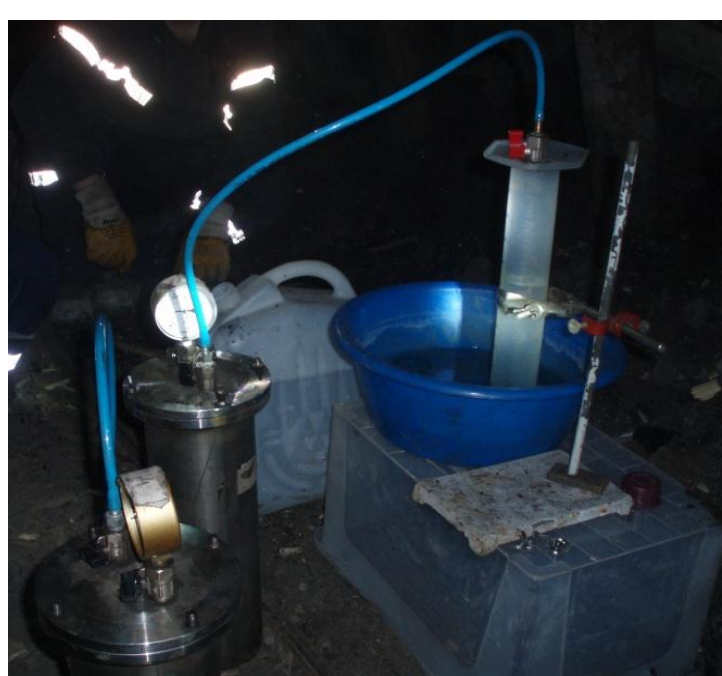

Şekil 6. Ocakta yerinde kullanılan kayıp gaz ölçüm düzeneği

Ocakta gerçekleştirilen bu ölçümlerden sonra, sızdırmaz kap içerisine alınan gaz örnekleri laboratuvara getirilmiş, vakit geçirilmeden desorbe gaz $\left(\mathrm{Q}_{2}\right)$ ölçümlerine başlanmıştır. Hızlı desorpisyon yöntemine uygun olarak iki gün boyunca yapılan ölçümleri takiben sızdırmaz kap, örneğin öğütülmesi ve kalıntı gaz $\left(\mathrm{Q}_{3}\right)$ miktarının belirlenmesine yönelik olarak bir tambur üzerine aktarılmış ve burada 5'er dakika'lık periyotlarla öğütme yapılmıştır. Her bir öğütme periyodundan sonra sızdırmaz kap ölçüm setine bağlanmış ve gaz yayılımı ölçümleri yapılmıştır. $Q_{1}, Q_{2}$ ve $Q_{3}$ ölçümlerinin sona ermesini takiben yukarıda bahsedilen standarda uygun şekilde hesaplamalar yapılmış ve ocaktan elde edilen örneğe ait kayıp gaz $\left(\mathrm{Q}_{1}\right)$, desorbe gaz $\left(\mathrm{Q}_{2}\right)$, kalıntı gaz $\left(\mathrm{Q}_{3}\right)$ ve toplam gaz içerikleri $\left(Q_{t}\right)$ hesaplanmıştır (Çizelge 2, Şekil 7).

Çizelge 2. Ocaktan alınan örneklere ait ölçüm sonuçları
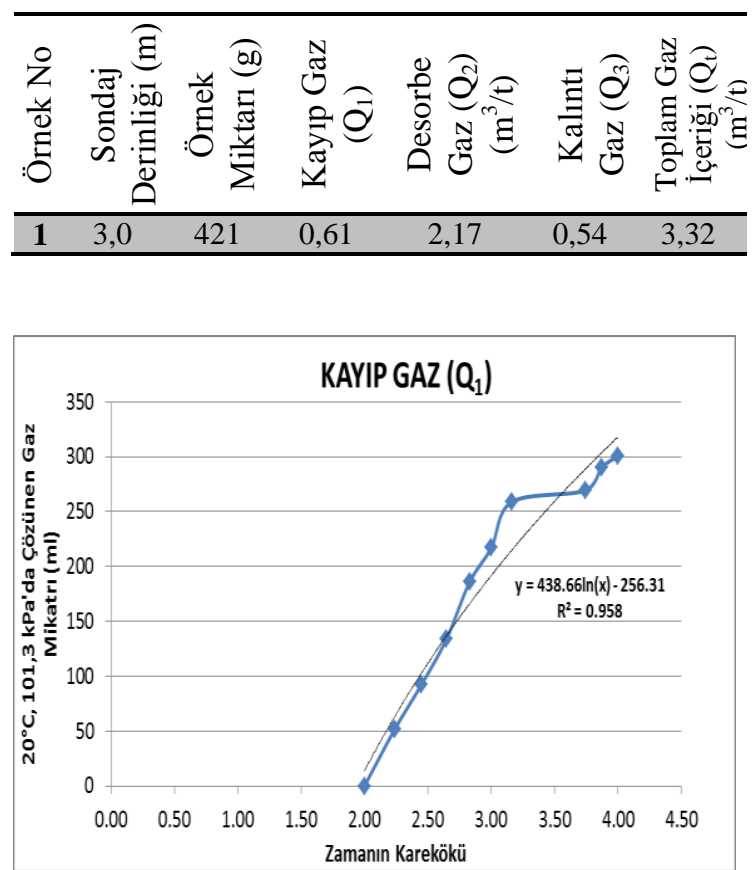

Şekil 7. Kayıp gaz $\left(Q_{1}\right)$ tahmin grafiği

\section{SONUÇLAR}

CEN-MA işletmesinin Gediz'deki ocağında çalışılmakta olan kömür damarının gaz içeriği 3-4 $\mathrm{m}^{3} / \mathrm{t}$ olarak kabul edilebilir. Buna göre, "düşük-orta" gaz içeriğine sahip bir damar olup desorpsiyon karakteri olarak ani püskürmelere yatkın değildir. 


\section{KAYNAKLAR}

1. Gray, L., 1987. Reservoir Engineering in Coal Seams: Part 1- The Physical Process of Gas Storage and Movement in Coal Seams, SPE Reservoir Engineering, 28-34.

2. Creedy, D.P., 1991. An Introduction to Geological Aspects of Methane Occurrence and Control in British Deep Coal Mines, Q Jour. Eng. Geol. Hydrogeol., 24: 209-220.

3. Noack, K., 1998. Control of Gas Emissions in Underground Coal Mines, Int. Jour. of Coal Geology, 35: 57-82.

4. Beamish, B.B., Crosdale, P.J., 1998. Instantaneous Outburst in Underground Coal Mines: An Overwiev and Association with Coal Type, Int. Jour. of Coal Geology, 35: 27-55.

5. Cao, Y., He, D., Glick, D.C., 2001. Coal and Gas Outburst in Footwalls of Reverse Faults, Int. Jour. of Coal Geology, 48: 47-63.

6. Wang, S., Elsworth, D., Liu, 2012. J., Mechanical Behaviour of Methane Infiltrated Coal: The Roles of Gas Desorption, Stress Level and Loading Rate, Rock Mech. Rock Eng. DOI: 10.1007/s00603-012-0324-0.

7. Curl, S.J., 1978. Methane Prediction in Coal Mines, IEA Coal research, London, Report Number ICTIS/TR04.

8. Osisanya, S.A., Schaffitzel, R.F., 1996. A Review of Horizontal Drilling and Completion Techniques for Recovery of Coalbed Methane, SPE Int. Conf. on Horizontal Well Technology, Society of Petroleum Engineers, Canada, November, 13p.

9. Mastalerz, M., Gluskoter, H., Rupp, J., 2004. Carbon Dioxide and Methane Sorption in High Volatile Bituminuous Coals from Indiana, International Journal of Coal Gelogy, Vol. 60, Issue 1, pp43-55.

10. Saghafi, A., 2010. Noval Methods of Coal Saem Gas Content Determination for Estimation of Greenhouse Gas Emissions from Mining", Proceedings of the 27th Annual International Pittsburgh Coal Conference, Istanbul, Turkey.

11. Gregg, S.J., Sing, K.S.W., 1982. Adsorption, Surface Area and Porosity, 2. Auflage, Vol. 86,
London: Wiley-VCH Verlag GmbH\&Co. $\mathrm{KGaA}$.

12. Marsh, H., 1987. Adsorption Methods to Study Microporosity in Coals and Carbons-A Critique, carbon, Vol. 25, No. 1, pp 49-58.

13. Lowell, S., Shields, J.E., 1991. Powder Surface Area and Porosity, Vol. 2, Springer.

14. Levy, J.H., Day, S.J., Killingley, J.S., 1997. Methane Capacities of Bowen Basin Coals Related to Coal Properties, Fuel, Vol. 76, No. 9, pp 813-819.

15. Crosdale, p.J., Beamish, B., Valiz, M., 1998. Coalbed Methane Sorption Related to Coal Composition, International Journal of Coal Gelogy, Vol. 35, No. 1, pp 147-158.

16. Clarkson, C. and Bustin, R., 1999. The Effect of Pore Structure and Gas Pressure upon the Transport Properties of Coal: A Laboratory and Modeling Study, 1. Isotherms and Pore VolumeDistributions, Fuel, Vol. 78, No. 11, pp 37-55.

17. Sobolik, J.L., Ludlow, D.K., 1992. Parametric Sensivity Comparison of the BET and DubininRadushkevich Models for Determining Char Suurface Area by $\mathrm{CO}_{2}$ Adsorption, Fuel, Vol. 71, No. 10, pp 1195-1202.

18. Lamberson, M.N., Bustin, R.M., 1993. Coalbed Methane Characteristics of Gates Formation Coals, Northeastern British Columbia: Effect of Maceral Composition. AAPGF bulltin, Vol. 77, No.12, pp 2062-2076.

19. Levine, J.R., 1993. Coalification: the Evaluation of Coal as Source Rock and Reservoir Rock for Oil and Gas, Hydrocarbons from Coal Oklahoma American Association of Petroleum Geolists.

20. Scott, A., 2002. Hydrogeologic Factors Affecting Gas Content Distribution in Coal Beds, Int. Jour. of Coal Geology, 50, 363-387.

21. Scott, A.R., Kaiser, W.R., 1996. Factors Affecting Gas-Content Distribution in Coal Beds: A Review", Expanded Abstracts, Rocky Mountain Section Meeting: American Association of Petroleum Geologists, 101-106.

22. Karayigit, A.I., Spears, D.A., Booth, C.A., 2000. Antimony and Arsenic Anomalies in the Coal Seams from the Gokler Coal Field, Gediz, Turkey, Int. Journal of Coal Geology, 44: 1-17. 
23. MTA, 2002. Türkiye Tersiyer Kömürlerinin Kimyasal ve Teknolojik Özellikleri, Ankara, s 227.

24. Demir, U., 2011. Kütahya Gediz Yöresi Kömürlerindeki Kükürdün Uzaklaştırılması, DPÜ, Fen Bilimleri Enstitüsü, Doktora Tezi, Kütahya, s 205.

25. MTA, 2010. Türkiye Linyit Envanteri, Ankara, s 234.

26. Battino, S., Doyle, J., 1983. The Determination of Gas Content of Coal from Boreholes, Ventilation of Coal Mines Symposium, Australian Ins. Of Min. And Met. Engineers, pp 6-1/6-5.

27. Nazarova, L.A., Nazarov, L.A., Polevshchika, Ya, Rodin, R.I., 2012. Inverse Problem Solution for Estimating Gas Content and Gas Diffusion Coefficient of Coal, Journal of Mining Science: 48(5), 781-788. 
